\title{
GCU
}

Glasgow Caledonian

University

University for the Common Good

\section{Predicting risk of pelvic floor disorders 12 and 20 years after delivery}

Jelovsek, J. Eric; Chagin, Kevin; Gyhagen, Maria; Hagen, Suzanne; Wilson, Don; Kattan, Michael W.; Elders, Andrew; Barber, Matthew D.; Areskoug, Björn; MacArthur, Christine; Milsom, Ian

Published in:

American Journal of Obstetrics and Gynecology

DOI:

10.1016/j.ajog.2017.10.014

Publication date:

2018

Document Version

Author accepted manuscript

Link to publication in ResearchOnline

Citation for published version (Harvard):

Jelovsek, JE, Chagin, K, Gyhagen, M, Hagen, S, Wilson, D, Kattan, MW, Elders, A, Barber, MD, Areskoug, B, MacArthur, C \& Milsom, I 2018, 'Predicting risk of pelvic floor disorders 12 and 20 years after delivery', American Journal of Obstetrics and Gynecology, vol. 218, no. 2, pp. 222.e1- 222.e19.

https://doi.org/10.1016/j.ajog.2017.10.014

\section{General rights}

Copyright and moral rights for the publications made accessible in the public portal are retained by the authors and/or other copyright owners and it is a condition of accessing publications that users recognise and abide by the legal requirements associated with these rights.

Take down policy

If you believe that this document breaches copyright please view our takedown policy at https://edshare.gcu.ac.uk/id/eprint/5179 for details of how to contact us. 


\section{PREDICTING RISK OF PELVIC FLOOR DISORDERS 12 AND 20 YEARS AFTER DELIVERY}

J. Eric Jelovsek ${ }^{1}$, Kevin Chagin ${ }^{1}$, Maria Gyhagen ${ }^{2}$, Suzanne Hagen $^{3}$, Don Wilson ${ }^{4}$, Michael W. Kattan ${ }^{1}$, Andrew Elders ${ }^{3}$, Matthew D. Barber ${ }^{1}$, Björn Areskoug $^{2}$, Christine MacArthur $^{5}$, Ian Milsom $^{2}$

${ }^{1}$ Obstetrics, Gynecology \& Women's Health Institute and Quantitative Health Sciences, Cleveland Clinic, Cleveland, Ohio, United States

${ }^{2}$ Department of Obstetrics \& Gynecology, Sahlgrenska Academy, University of Gothenburg, Gothenburg, ${ }^{3}$ Nursing, Midwifery and Allied Health Professions Research Unit, Glasgow Caledonian University, Glasgow, United Kingdom

${ }^{4}$ University of Otago, Dunedin, New Zealand

${ }^{5}$ Institute of Applied Health Research, University of Birmingham, Birmingham, UK

Corresponding author

J. Eric Jelovsek, MD MMEd

209 Baker House, DUMC 3084, Duke University Medical Center, Durham, NC

Phone: 919-668-5889, email: eric.jelovsek@ duke.edu

\section{Declaration of interests}

Jelovsek - Royalties, UpToDate; Chagin - No conflicts; Barber - Royalties, UpToDate, Elsevier; Maria Gyhagen - Honoraria - Astellas Pharma for speaker participation; Suzanne Hagen - No conflicts; Don Wilson - No conflicts; Michael Kattan - No conflicts; Andrew Elders - University of Gothenburg; Bjorn Areskoug - No conflicts; Christine MacArthur - No conflicts; Ian Milsom - Grant (National LUA/ALF Grant no 11315), Honorarium for lecture (SCA, Astellas, Allergan).

\section{Funding Sources}

\section{Sweden}

- National LUA/ALF grant nr 11315 Region of Västra Götaland, Sweden

- The Göteborg Medical Society

- Hjalmar Svenssons Fund

UK/New Zealand

- Wellbeing of Women/Royal College of Obstetricians and Gynaecologists

- Health Research Council of New Zealand 


\section{ABSTRACT}

Background: Little progress has been made in preventing pelvic floor disorders despite their significant health and economic impact. Identifying women at risk remains a key element in targeting prevention and planning health resource allocation strategies. Although events around the time of childbirth are clinically recognized as important predictors, it is difficult to counsel women and intervene around the time of childbirth due to an inability to accurately convey a patient's risk in the presence of multiple risk factors and the long time lapse, often decades, between obstetric events and the onset of pelvic floor disorders later in life. Prediction models and scoring systems have been used in other areas of medicine to identify patients at risk for chronic diseases. Models have been developed for use before delivery that predict short-term risk of pelvic floor disorders after childbirth but no models predicting long-term risk exist.

Objective: To use variables known before and during childbirth to develop and validate prognostic models estimating risks of these disorders 12 and 20 years after delivery.

Study Design: Obstetric variables were collected from two cohorts: 1) women who gave birth in the United Kingdom and New Zealand (n=3763) and 2) women from the Swedish Medical Birth Register $(n=4991)$. Pelvic floor disorders were self-reported 12 years after childbirth in the UK/NZ cohort and 20 years after childbirth in the Swedish Register. The cohorts were split so that data during the first half of the cohort's time period were used to fit prediction models and validation was performed from the second half (temporal validation). As there is currently no consensus on how to best define pelvic floor disorders from a patient's perspective, we chose to fit the data for each model using multiple outcome definitions for prolapse, urinary incontinence, fecal incontinence, 1 or more pelvic floor disorder and 2 or more pelvic floor disorders. Model accuracy was measured: 1) by ranking an individual's risk among all subjects in the cohort (discrimination) using a concordance index and 2) by observing whether the predicted probability was too high or low (calibration) at a range of predicted probabilities using visual plots. 
Results: Models were able to discriminate between women who developed bothersome symptoms or received treatment, at 12 and 20 years respectively, for: pelvic organ prolapse (concordance indices 0.570 , 0.627), urinary incontinence (concordance indices $0.653,0.689$ ), fecal incontinence (concordance indices $0.618,0.676$ ), $\geq 1$ pelvic floor disorders (concordance indices $0.639,0.675$ ) and $\geq 2$ pelvic floor disorders (concordance indices $0.635,0.619$ ). The discriminatory ability of all models is shown in Table 2 . Route of delivery and family history of each pelvic floor disorder were strong predictors in most models. Urinary incontinence before and during the index pregnancy was a strong predictor for developing all pelvic floor disorders in most models 12 years after delivery. The 12 and 20-year bothersome or treatment for prolapse models were accurate when providing predictions for risk from $0 \%$ to approximately $15 \%$. The 12-year and 20-year primiparous model began to over-predict when risk rates reached $20 \%$. When predicting bothersome symptoms or treatment for urinary incontinence, the 12-year models were accurate when predictions ranged from approximately $5 \%$ to $60 \%$ and 20 -year primiparous models were accurate between $5 \%$ and $80 \%$. For bothersome symptoms or treatment for fecal incontinence, the 12 and 20 -year models were accurate between $1 \%$ and $15 \%$ risk and began to over-predict at rates above $15 \%$ and $20 \%$, respectively.

Conclusion: Models may provide an opportunity before birth to identify women at low risk of developing pelvic floor disorders and institute prevention strategies such as pelvic floor muscle training, weight control or elective cesarean section for women at higher risk. Models are provided at: http://riskcalc.org/UR CHOICE/

\section{INTRODUCTION}


Pelvic floor disorders such as pelvic organ prolapse, urinary incontinence and fecal incontinence constitute a huge global health problem affecting millions of women throughout the world. The prevalence of pelvic floor disorders has been reported to be $46 \%$ and many women have more than one. ${ }^{1}$ Pelvic floor disorders can have a negative influence on a woman's well- being, quality of life, body image and sexual function, and prevent many from participating in recreational and sporting activities. ${ }^{1,2}$ The global costs of pelvic floor disorders to health care systems and society are enormous. ${ }^{1,3}$ Approximately, 1 in 5 women will undergo surgery for prolapse or urinary incontinence by age $85 .{ }^{4,5}$ Current treatments, often surgical, carry risks and relatively high rates of recurrence. ${ }^{6,7}$

Little progress has been made in preventing pelvic floor disorders despite their significant health and economic impact. ${ }^{8}$ Identifying women at risk remains a key element in targeting prevention and planning health resource allocation strategies. The etiology of pelvic floor disorders is known to be multifactorial and obstetric trauma during childbirth is one of the most important identifiable risk factors. ${ }^{1}$ Numerous epidemiological studies indicate an increased prevalence of pelvic floor disorders with increasing parity with the greatest increase in risk attributed to the birth of the first child. ${ }^{1}$ Although events around the time of childbirth are clinically recognized as important predictors, many women undergo the labor and delivery process and do not experience long-term pelvic floor dysfunction. At present, it is difficult to counsel women and intervene around the time of childbirth due to an inability to accurately convey a patient's risk in the presence of multiple risk factors and the long time lapse, often decades, between obstetric events and the onset of pelvic floor disorders later in life.

Prediction models and scoring systems have been used in other areas of medicine to identify patients at risk for chronic diseases. ${ }^{9,10}$ Models have been developed for use before delivery that predict short-term risk of pelvic floor disorders after childbirth but no models predicting long-term risk exist. ${ }^{11,12}$ The aims of this study were to construct and validate models capable of predicting the development of pelvic floor disorders 12 and 20 years after delivery using data from two large independent international cohort studies. ${ }^{13,14}$ Such models have potential to provide individual women more accurate predictions than the 
current standard of care given: 1) the paucity of existing tools, 2) the large amount of variability in the predicted rates of pelvic floor disorders provided by clinicians in practice and 3) the increasing evidence that clinical prediction models consistently show superiority over expert clinicians because they avoid common cognitive biases. ${ }^{15,16}$

\section{METHODS}

This study is reported using methods set forth in the Transparent Reporting of a multivariable prediction model for Individual Prognosis Or Diagnosis (TRIPOD): the TRIPOD Statement. ${ }^{17}$ The study population consisted of two longitudinal, prospective cohort studies. The PROlapse and incontinence LONG-term (ProLong) study aimed to determine whether delivery mode was predictive of pelvic floor disorders in 10,989 primiparous and multiparous women 12 years after the index birth. ${ }^{14}$ The second cohort was the Swedish Pregnancy, Obesity and Pelvic Floor (SwePOP) study. The aim of SwePOP was to compare the prevalence of pelvic floor disorders in a cohort of 10,117 primiparous women identified from the Swedish Medical Birth Register 20 years after one delivery. ${ }^{13,18}$ Both studies were designed to investigate delivery mode as a predictor of pelvic floor disorders and therefore, captured key maternal, labor and delivery variables that were known at that time to be potential risk factors of pelvic floor disorders. Study details have been previously published and are summarized in Figure $1 .{ }^{14,18}$

In the ProLong study, prolapse symptoms were measured using the validated Pelvic Organ Prolapse Symptom Score. ${ }^{19}$ Urinary and fecal incontinence questions were designed by the study team because at the time of recruitment (1993/94) there were no suitable validated questionnaires on incontinence. Family history was measured using a response of either "yes" or "no" to, "Have any of your blood relatives ever had a prolapse?" and "If yes, how are they related to you (eg. mother, sister)?" In the SwePOP study, prolapse was defined using the validated SPOP questionnaire, ${ }^{20}$ urinary incontinence using the Sandvik severity scale ${ }^{21}$ and fecal incontinence using the Wexner score. ${ }^{22}$ Family history was measured using a response of either yes or no to each of the following items, "Has your mother suffered from urinary 
leakage?", "Has your mother suffered from prolapse?" and "Has your mother suffered from leakage of flatus/gas or feces?" Each study received ethics committee approval at all centers. Written informed consent was obtained from participants in both studies.

In order to allow for temporal validation, each cohort was temporally split so that women giving birth in the first half of the cohort's time period were considered for the training dataset and used to build each model. For the ProLong dataset, data from primiparous and multiparous women who gave birth between September 11, 1993 and May 1, 1994 and responded at 12 years $(\mathrm{N}=2,095)$ were used to build models to predict 12-year outcomes for women who gave birth between May 2, 1994 and November 11, 1994 $(\mathrm{N}=1,668)$. Similarly, in the SwePOP dataset, data from primiparous women who gave birth between January 1, 1985 and June 30, $1987(\mathrm{~N}=2,607)$ were used to build models to predict 20-year outcomes for women who gave birth between July 1, 1987 and December 31, 1988 (N=2,384). For each training dataset, the multiple imputation using chained equations (MICE) method was used to calculate missing values for predictors. ${ }^{23}$ Predictors for the test dataset and outcomes for all models were based on actual, not imputed values.

As there is currently no consensus on how to best define pelvic floor disorders from a patient's perspective, we chose to fit the data for each model using multiple outcome definitions for prolapse, urinary incontinence, fecal incontinence, 1 or more pelvic floor disorder and 2 or more pelvic floor disorders. We developed models to predict: 1) the presence of "any symptoms" regardless of severity; 2) the presence of bothersome symptoms; 3) treatment for the disorder, or 4) the combination of either bothersome symptoms or receiving treatment for each disorder (prolapse, urinary incontinence, fecal incontinence) and their combination (any pelvic floor disorder or 2 or more pelvic floor disorders) (Table 1 footnote). Data are only presented for category 4) above, and all remaining outcomes are available in the supplementary results. 
Multiple logistic regression models were fit to the training data consisting of the full set of candidate predictors and each outcome. Harrell's "Model Approximation" process of backwards elimination was used to rank the variables in order of importance starting from the full model using a bootstrap biascorrected concordance index as the stopping criteria to find the best parsimonious model. ${ }^{24}$ Variables with individual p-values that were greater than 0.05 were left in the model if they offered information to improve the overall model accuracy. Removal was evaluated by determining which variable had the smallest effect on the $\mathrm{R}^{2}$ and was stopped when the bootstrap concordance index had a change less than 0.01. This process provided a parsimonious model for each outcome.

Model accuracy was measured: 1) by ranking an individual's risk among all subjects in the cohort (discrimination) using a concordance index and 2) by observing whether the predicted probability was too high or low (calibration) at a range of predicted probabilities using visual plots. Once the models were built and prior to performing temporal validation, all concordance indices were internally validated using 1,000 bootstrap samples to adjust for overfitting biases on the initial build and $95 \%$ confidence intervals were calculated. Calibration curves along with distributions of predicted probabilities of those with and without each outcome were generated to visually observe how close model predictions were to actual predictions.

Temporal validation requires a prognostic model to produce accurate predictions when it is tested in cohorts from different time periods. It is a prospective form of validation recommended when an independent validation data set with similar obstetric populations and long-term outcomes is not available. ${ }^{17}$ Models were developed using antepartum variables, previous delivery variables and delivery mode. We specifically investigated whether events that occurred at the time of delivery (e.g. episiotomy, perineal laceration) significantly improved the accuracy of prediction by comparing the difference in accuracy using a bootstrap method from their respective receiver operating characteristic curve. 
All models were combined into a single integrated web-based calculator so that a complete set of predictors can be entered and outcomes for all pelvic floor disorders are presented. All analyses were performed using R Version 3.2.3 (2015-12-10).

\section{RESULTS}

Baseline characteristics and outcomes were available in 3763 participants in the ProLong study 12 years after their index birth and 4991 of the participants in the SwePOP study 20 years after their first and only birth. The overall rates of pelvic floor disorders with $95 \%$ confidence intervals 12 and 20 years after delivery are described in Table 1 . The descriptive statistics of candidate predictors among each study cohort are provided in Supplemental Table 1.

\section{Model Discrimination}

Forty separate models were developed from the two cohorts for use including 20 models that predict outcomes in primiparous and multiparous women 12 years after delivery and 20 models that predict outcomes in primiparous women 20 years after delivery. All 40 final models included predictors known or estimated prior to delivery along with actual route of delivery. Each model's discriminatory ability is shown in Table 2. Models were able to discriminate between women who developed bothersome symptoms or received treatment, at 12 and 20 years respectively, for pelvic organ prolapse (concordance indices $0.570,0.627$ ), urinary incontinence (concordance indices $0.653,0.689$ ), fecal incontinence (concordance indices $0.618,0.676$ ), one or more pelvic floor disorders (concordance indices $0.639,0.675$ ) and two or more pelvic floor disorders (concordance indices $0.635,0.619$ ).

\section{Model Calibration}

Calibration curves for the models from the two cohorts predicting bothersome pelvic floor disorders or the need for treatment at 12 and 20 years are shown in Figure 2. The majority of models predicted probabilities close to actual probabilities throughout a range of clinically useful predictions but began to 
over-predict at higher probabilities. The 12 and 20-year bothersome or treatment for prolapse models were accurate when providing predictions for risk from $0 \%$ to approximately 15\% (Table 1 average risk 7-10\%). The 12-year and 20-year primiparous model began to over-predict when risk rates reached $20 \%$. When predicting bothersome symptoms or treatment for urinary incontinence, the 12-year models were accurate when predictions ranged from approximately 5\% to 60\% (Table 1 average risk 23-31\%) and 20year primiparous models were accurate between 5\% and 80\% (Table 1 average risk 18-20\%). For bothersome symptoms or treatment for fecal incontinence, the 12 and 20-year models were accurate between $1 \%$ and $15 \%$ risk (Table 1 average risk 3-7\%). The bothersome or treatment for fecal incontinence models began to over-predict at rates above $15 \%$ and $20 \%$ for the 12 and 20 -year model, respectively. A complete set of calibration curves for models predicting all outcomes at 12 and 20 years are available in Supplemental Figures $\underline{1 \mathrm{~A}}$ and $\underline{1 \mathrm{~B}}$. An online calculator (http://riskcalc.org/UR_CHOICE/) is available for clinical use and two examples of predictions for a hypothetical average and high-risk patient are displayed. (Supplemental Figure $\underline{2 \mathrm{~A}}$ and $\underline{2 \mathrm{~B}}$ )

\section{Model Variables}

The relative influence of each predictor for models predicting the combination of bothersome symptoms or receiving treatment for each disorder is summarized in Figure 3 . Route of index delivery, number of previous births and family history of each pelvic floor disorder were the most influential in most models. Any urinary incontinence before pregnancy was an influential predictor for women developing bothersome prolapse or having treatment for prolapse, urinary incontinence and fecal incontinence 12 years after delivery. In primiparous women at 20 years, having a vaginal delivery was significantly associated with increasing a woman's 20 -year risk of developing bothersome or treatment for prolapse and urinary incontinence. The strength of association among the predictors for all models are provided in Supplemental Figures $\underline{3 \mathrm{~A}}$ and $\underline{3 \mathrm{~B}}$.

\section{DISCUSSION}


Most women undergo childbirth without experiencing bothersome pelvic floor disorders or requiring treatment for pelvic floor disorders throughout their lifespan. More recently, women are seeking more evidence-based informed decision making prior to labor that will reassure them that the birthing process will not be detrimental to their long-term health. Informing a woman of her risks of pelvic floor disorders along with other risks of childbirth, is in accordance with the judgment of the 2015 United Kingdom Supreme Court case and supports a woman's autonomy and her right to informed choice regarding her care in pregnancy and childbirth. ${ }^{25}$ A major barrier to effective prevention of pelvic floor disorders is the inability to identify "at risk" women to target prevention programs. Childbirth is among the most important and consistent risk factor for pelvic floor disorders, however, in most women, clinically relevant symptoms and treatment occur decades later in life. ${ }^{26}$ The models presented, while not perfect, predict better than chance and are able to discriminate between those with and without pelvic floor disorders $51-75 \%$ of the time. Traditionally, when estimates of risk are provided to women during pregnancy, they are based on a clinician's knowledge and experience, by quoting overall average population risk to all women, or by heuristically assigning individuals into crude categories such as low or high-risk groups. Even when high-level evidence exists, estimates are typically provided without accurately accounting for the specifics of a woman's unique characteristics such as her age, parity, comorbidities and family history. The development and implementation of accurate clinical tools that go beyond clinical judgment and predict an individual woman's future risk of developing pelvic floor disorders will be an essential component of any primary prevention strategy and will help reassure the majority of mothers when serious pelvic floor damage is not strongly predicted.

We developed models for multiple definitions of each pelvic floor disorder outcome, combined into a single, easy-to-use, on-line calculator. The models allow calculation of risk that includes past delivery characteristics and planned route of delivery (vaginal versus cesarean section). The role of elective cesarean section in the prevention of pelvic floor disorders remains controversial and, given the potential maternal and fetal risks, is unlikely to be an effective prevention strategy for most women. ${ }^{26,27}$ It has been 
estimated, for instance, that approximately 9 cesarean sections would be necessary to prevent urinary incontinence in one primiparous woman of average risk. ${ }^{18}$ However, a strategy of offering cesarean section to women who are at substantially higher than average risk for pelvic floor disorders may be a more appropriate and effective prevention strategy. At what risk threshold that occurs is currently unknown however, and must be balanced against the risks of cesarean section and, in many cases, multiple repeat cesarean deliveries, especially since maximum protection may occur when all deliveries are by Cesarean. ${ }^{14,26}$ After delivery, the models are intended for women who may be considering other secondary prevention strategies. Prevention strategies such as pelvic floor muscle training and weight loss programs offer promise but have not been adequately studied long-term or many years after delivery. ${ }^{28}$ Compliance with long-term prevention programs is a significant challenge and may be improved by informing women about their individual risk of developing the disorders. ${ }^{29}$

The major strengths of this analysis are the application of predictive analytics to two large well-described cohorts of women that collected common maternal and obstetrical variables and similarly defined pelvic floor disorder outcomes 12 and 20 years after delivery. While not racially diverse, together these cohorts do provide important geographic and cultural diversity, which are important for conditions affecting quality of life. However, there are important differences in the two cohorts. The ProLong dataset includes primiparous and multiparous women and reports outcomes at 12 years after delivery, while the SwePOP study included only primiparous women and reported outcomes at 20 years after delivery. Because of these differences, we chose not to develop our prediction models in one cohort and then externally validate them in the other as is commonly done. Instead, we performed temporal validation in each separate cohort, which is a stronger approach than the more commonly performed random splitting of a dataset into a development and validation cohort. ${ }^{17}$

An important limitation of our models is that they are not perfect. In spite of this, they advance our current abilities to predict an individual's risk of developing pelvic floor disorders many years after 
childbirth better than providing highly variable, average event rates. The models in this analysis provide similar discrimination to other predictive models currently used in clinical practice whose concordance indices generally range from 0.6 to 0.8 including widely-used models such as the National Cancer Institute Gail model for prediction of Breast Cancer risk (concordance index 0.59) and the Framingham Cardiovascular Risk Model (concordance index 0.72). ${ }^{9,30}$ While the models developed in this analysis were well calibrated at clinical decision-making thresholds, some models provide higher than actual probabilities when rates of actual outcomes are high and where there were fewer outcome events available.

In summary, the models provide individualized prediction of risk of developing pelvic floor disorders 12 and 20 years after delivery using maternal and obstetrical variables available prior to childbirth. These models should help identify high-risk women in whom prevention strategies such as pelvic floor muscle training and weight control or elective cesarean section might be targeted. Ideally, external validation of the models should be conducted when and if other large cohorts with similar follow-up become available. 


\section{REFERENCES}

1. Milsom I, Altman D, CARTWRight R, ET AL. Epidemiology of Urinary Incontinence (UI) and other Lower Urinary Tract Symptoms (LUTS), Pelvic Organ Prolapse (POP) and Anal Incontinence (AI). In: Abrams P, Cardozo L, Khoury S, Wein A, eds. 5th International Consultation on Incontinence. Paris: Health Publications, Ltd., 2013.

2. CoYne KS, SEXTON CC, IRWIN DE, Kopp ZS, KELLEHER CJ, MiLSOM I. The impact of overactive bladder, incontinence and other lower urinary tract symptoms on quality of life, work productivity, sexuality and emotional well-being in men and women: results from the EPIC study. BJU Int 2008;101:1388-95.

3. MOORE K, WAGNER TH, SUBAK L, et al. Economics of urinary and faecal incontinence, and prolapse. In: Abrams P, Cordozo L, Koury S, Wein A, eds. Incontinence. Paris: Health Publications Ltd., 2012.

4. HAYA N, BAESSLER K, ChRISTMANN-SCHMid C, et al. Prolapse and continence surgery in countries of the Organization for Economic Cooperation and Development in 2012. Am J Obstet Gynecol 2015;212:755 e1-55 e27.

5. Wu JM, MATTHEWS CA, CONOVER MM, PATE V, JONSSON FUnK M. Lifetime risk of stress urinary incontinence or pelvic organ prolapse surgery. Obstet Gynecol 2014;123:1201-6.

6. FORD AA, ROGERSON L, CODY JD, OGAH J. Mid-urethral sling operations for stress urinary incontinence in women. Cochrane Database Syst Rev 2015:CD006375.

7. MAHER C, FEINER B, BAESSLER K, SCHMID C. Surgical management of pelvic organ prolapse in women. The Cochrane database of systematic reviews 2013;4:CD004014.

8. NIDDK, OFFICE OF RESEARCH ON WOMEN'S H, NATIONAL INSTITUTE ON A. Prevention of Lower Urinary Tract Symptoms in Women: Bladder Health Clinical Centers (PLUS-CCs) (U01). National Institutes of Health, 2014 website: https:/grants.nih.gov/grants/guide/rfafiles/RFA-DK-14-004.html.

9. D'AGOSTINO RB, SR., GRUNDY S, SUlLiVAN LM, WILSON P, GRoup CHDRP. Validation of the Framingham coronary heart disease prediction scores: results of a multiple ethnic groups investigation. JAMA 2001;286:180-7.

10. LYSSENKO V, JONSSON A, ALMGREN P, et al. Clinical risk factors, DNA variants, and the development of type 2 diabetes. N Engl J Med 2008;359:2220-32.

11. JELOVSEK JE, PicCorElli A, BARBER MD, TUNitSKY-BitTon E, KATTAN MW. Prediction models for postpartum urinary and fecal incontinence in primiparous women. Female Pelvic Med Reconstr Surg 2013;19:110-8.

12. WILSON D, DORNAN J, MILSOM I, FREEMAN R. UR-CHOICE: can we provide mothers-to-be with information about the risk of future pelvic floor dysfunction? Int Urogynecol J 2014;25:1449-52.

13. GyHAGEN M, BULLARBO M, NIELSEN TF, MiLSOM I. Prevalence and risk factors for pelvic organ prolapse 20 years after childbirth: a national cohort study in singleton primiparae after vaginal or caesarean delivery. BJOG 2013;120:152-60.

14. MacARthur C, GLAZENER C, LANCASHire R, HERbison P, Wilson D, ProLong STUdy G. Exclusive caesarean section delivery and subsequent urinary and faecal incontinence: a 12-year longitudinal study. BJOG 2011;118:1001-7.

15. JELOVSEK JE, CHAGIN K, BRUBAKER L, et al. A model for predicting the risk of de novo stress urinary incontinence in women undergoing pelvic organ prolapse surgery. Obstet Gynecol 2014;123:279-87.

16. KatTAn MW, O'Rourke C, Yu C, Chagin K. The Wisdom of Crowds of Doctors: Their Average Predictions Outperform Their Individual Ones. Med Decis Making 2016;36:536-40. 
17. Collins GS, Reitsma JB, ALTMAN DG, Moons KG. Transparent reporting of a multivariable prediction model for Individual Prognosis or Diagnosis (TRIPOD): the TRIPOD statement. J Clin Epidemiol 2015;68:134-43.

18. GyHAGEN M, BulLARBO M, NiELSEN TF, Milsom I. The prevalence of urinary incontinence 20 years after childbirth: a national cohort study in singleton primiparae after vaginal or caesarean delivery. BJOG 2013;120:144-51.

19. Hagen S, Glazener C, Sinclair L, STARK D, BugGe C. Psychometric properties of the pelvic organ prolapse symptom score. BJOG 2009;116:25-31.

20. Tegerstedt G, Miedel A, MAehle-Schmidt M, Nyren O, HAMmARSTRom M. A short-form questionnaire identified genital organ prolapse. J Clin Epidemiol 2005;58:41-6.

21. SANDVIK H, HUNSKAAR S, SEIM A, HERMSTAD R, VANVIK A, BRATT H. Validation of a severity index in female urinary incontinence and its implementation in an epidemiological survey. J Epidemiol Community Health 1993;47:497-9.

22. JORGE JM, WEXNER SD. Etiology and management of fecal incontinence. Dis Colon Rectum 1993;36:77-97.

23. WHITE IR, ROYSTON P, WoOD AM. Multiple imputation using chained equations: Issues and guidance for practice. Stat Med 2011;30:377-99.

24. HARRELL FE. Regression modeling strategies: with applications to linear models, logistic regression, and survival analysis. New York: Springer.

25. SOKOL DK. Update on the UK law on consent. BMJ 2015;350:h1481.

26. LANDEFELD CS, BOWERS BJ, FELD AD, et al. National Institutes of Health state-of-the-science conference statement: prevention of fecal and urinary incontinence in adults. Ann Intern Med 2008;148:449-58.

27. VISCO AG, VISWANATHAN M, LOHR KN, et al. Cesarean delivery on maternal request: maternal and neonatal outcomes. Obstet Gynecol 2006;108:1517-29.

28. HAGEN S, GLAZENER C, MCCLURG D, et al. Pelvic floor muscle training for secondary prevention of pelvic organ prolapse (PREVPROL): a multicentre randomised controlled trial. Lancet 2017;389:393-402.

29. NATIONAL CANCER I. Theory at a Glance: A guide for health promotion practice. National Institutes of Health: US Department of Health and Human Services, National Institutes of Health, 2012 (vol 2016).

30. Rockhill B, SPIEgelman D, BYRne C, HunTER DJ, Colditz GA. Validation of the Gail et al. model of breast cancer risk prediction and implications for chemoprevention. J Natl Cancer Inst 2001;93:358-66. 


\section{Acknowledgement}

We would like to acknowledge the contribution of Professors Bob Freeman [Plymouth, UK] and Jim Dornan [Belfast, UK] to the concept of predicting risk of subsequent pelvic floor dysfunction after pregnancy and delivery.

\section{Role of the Funding Source}

The study sponsors did not participate in the study design, collection, analysis and interpretation of the data; the writing of the report or the decision to submit the paper for publication. The corresponding author confirms that he had full access to all the data in the study and had final responsibility for the decision to submit for publication.

\section{Declaration of interests}

Jelovsek - Royalties, UpToDate; Chagin - No conficts; Barber - Royalties, UpToDate, Elsevier; Maria Gyhagen - Honoraria - Astellas Pharma for speaker participation; Suzanne Hagen - No conflicts; Don Wilson - No conflicts; Michael Kattan - No conflicts; Andrew Elders - University of Gothenburg; Bjorn Areskoug - No conflicts; Christine MacArthur - No conflicts; Ian Milsom - Grant (National LUA/ALF Grant no 11315), Honorarium for lecture (SCA, Astellas, Allergan).

\section{Author Contributions:}

Study concept and design - Jelovsek, Chagin, Gyhagen, Hagen, Wilson, Kattan, Elders, Barber, Areskoug, MacArthur, Milsom

Acquisition of data - Jelovsek, Chagin, Gyhagen, Hagen, Wilson, Kattan, Elders, Barber, Areskoug, MacArthur, Milsom

Analysis and interpretation of data - Jelovsek, Chagin, Gyhagen, Hagen, Wilson, Kattan, Elders, Barber, Areskoug, MacArthur, Milsom 
Drafting of the manuscript - Jelovsek, Chagin, Gyhagen, Hagen, Wilson, Kattan, Elders, Barber, Areskoug, MacArthur, Milsom

Critical revision of the manuscript for important intellectual content - Jelovsek, Chagin, Gyhagen, Hagen, Wilson, Kattan, Elders, Barber, Areskoug, MacArthur, Milsom

\section{List of Manuscript Tables}

1. Table 1 - Overall rates of pelvic floor disorders with $95 \%$ confidence intervals 12 and 20 years after delivery.

2. Table $2-$ Discrimination of risk using concordance indices for models to predict pelvic floor disorders 12 and 20 years after delivery.

3. Supplemental Table 1- Descriptive study characteristics for ProLong and SwePop cohorts.

\section{List of Manuscript Figures}

1. Figure 1 - Participant flow diagram. *denotes imputation was performed.

2. Figure 2 - Calibration curves for before delivery models predicting bothersome pelvic floor disorder or needing treatment for a pelvic floor disorder 12 and 20 years after delivery. The horizontal axis is the predicted probability provided by the model and the vertical axis is the actual probability of the outcome. Plots were inspected for predicted probabilities to remain close to actual probabilities (the 45-degree line) within the range of probabilities where patient or clinical decisions are made. When the dotted line is under the dashed 45-degree line the model provides predictions that are higher than actual probabilities (over-prediction) and if the dotted line is over the dashed 45-degree line the model provides predictions that are lower than actual probabilities (under-prediction).

3. Figure 3-Odds ratios for predictors in the models predicting bothersome pelvic organ prolapse, urinary incontinence or fecal incontinence or needing treatment for these conditions 12 and 20 years after delivery. POP, pelvic organ prolapse; UI, urinary incontinence; FI, fecal incontinence. 
Each box indicates the odd ratio of each variable included in the model with horizontal line indicating the $95 \%$ CI. If the horizontal line and box are green then the variable was significant at a level of 0.05. An arrow indicates that the line or the odd ratio extend off of the plot.

4. Supplementary Figure 1 - Calibration curves for all models predicting pelvic floor disorders 12 (Figure 1A) and 20 years (Figure 1B) after delivery.

5. Supplementary Figure 2 - Example of the UR-CHOICE online calculator for models predicting pelvic floor disorders 20 years after delivery. Figure 2A and 2B show a 28 -year-old primigravid woman who weighs 150 pounds, height is 5 feet 4 inches, estimated infant weight is 7 pounds 2 ounces, head circumference is $35 \mathrm{~cm}$, and has no history of urinary incontinence before or during pregnancy. The average risk patient (Figure 2A) has no family history of pelvic organ prolapse, urinary or fecal incontinence and the high-risk patient (Figure 2B) has a positive family history of pelvic organ prolapse and urinary incontinence as well as urinary incontinence during her pregnancy.

6. Supplementary Figure 3 - Odds ratio of each variable included in before delivery models predicting pelvic floor disorders 12 (Figure 3A) and 20 (Figure 3B) years after delivery. Each box indicates the odd ratio of each variable included in the model with horizontal line indicating the 95\% CI. If the horizontal line and box are green then the variable was significant at a level of 0.05. An arrow indicates that the line or the odd ratio extend off of the plot. 
Table 1 Overall rates of pelvic floor disorders with 95\% confidence intervals in primiparous and multiparous women 12 years after childbirth in the ProLong study and in primiparous women 20 years after childbirth in the SwePop study

\begin{tabular}{|c|c|c|c|c|c|c|c|c|c|}
\hline & Parity & $\mathbf{N}$ & $\begin{array}{c}\text { Any } \\
\%(95 \% \mathrm{Cl})\end{array}$ & $\mathbf{N}$ & $\begin{array}{c}\text { Bothersome } \\
\%(95 \% \mathrm{Cl})\end{array}$ & $\mathbf{N}$ & $\begin{array}{l}\text { Treatment } \\
\%(95 \% \mathrm{Cl})\end{array}$ & $\mathbf{N}$ & $\begin{array}{l}\text { Bothersome or } \\
\text { Treatment } \\
\%(95 \% \mathrm{Cl})\end{array}$ \\
\hline \multicolumn{10}{|c|}{ Pelvic organ prolapse $^{+}$} \\
\hline 12 -years & 0 & 291 & $17 \%(15.1 \%, 18.7 \%)$ & 102 & $6 \%(4.8 \%, 7.0 \%)$ & 28 & $2 \%(1.2 \%, 2.6 \%)$ & 126 & $8 \%(7.0 \%, 9.8 \%)$ \\
\hline 20-years & 0 & 646 & $13 \%(12.1 \%, 14.0 \%)$ & 300 & $6 \%(5.4 \%, 6.7 \%)$ & 73 & $1.5 \%(1.2 \%, 1.9 \%)$ & 346 & $7 \%(6.6 \%, 8.1 \%)$ \\
\hline 12-years & $\geq 1$ & 347 & $17 \%(15.4 \%, 18.7 \%)$ & 111 & $5 \%(4.5 \%, 6.4 \%)$ & 61 & $3 \%(2.6 \%, 4.3 \%)$ & 159 & $9 \%(7.6 \%, 10.3 \%)$ \\
\hline \multicolumn{10}{|c|}{ Urinary incontinence $^{++}$} \\
\hline 12 -years & 0 & 877 & $51 \%(48.5 \%, 53.3 \%)$ & 380 & $22 \%(20.2 \%, 24.2 \%)$ & 83 & $5 \%(3.9 \%, 6.0 \%)$ & 423 & $25 \%(23.2 \%, 27.4 \%)$ \\
\hline 20-years & 0 & 1895 & $38 \%(36.9 \%, 39.6 \%)$ & 822 & $17 \%(15.7 \%, 17.8 \%)$ & 163 & $3 \%(2.9 \%, 3.9 \%)$ & 902 & $19 \%(17.9 \%, 20.1 \%)$ \\
\hline 12-years & $\geq 1$ & 1103 & $54 \%(52.0 \%, 56.4 \%)$ & 510 & $25 \%(23.5 \%, 27.3 \%)$ & 113 & $6 \%(4.7 \%, 6.8 \%)$ & 564 & $29 \%(26.8 \%, 30.8 \%)$ \\
\hline \multicolumn{10}{|c|}{ Fecal incontinence ${ }^{+++}$} \\
\hline 12-years & 0 & 203 & $12 \%(10.3 \%, 13.4 \%)$ & 42 & $2 \%(1.7 \%, 3.2 \%)$ & 37 & $2 \%(1.5 \%, 2.9 \%)$ & 68 & $4 \%(3.2 \%, 5.1 \%)$ \\
\hline 20-years & 0 & 671 & $14 \%(12.6 \%, 14.5 \%)$ & 112 & $2 \%(1.8 \%, 2.7 \%)$ & 54 & $1 \%(0.8 \%, 1.4 \%)$ & 145 & $3 \%(2.5 \%, 3.5 \%)$ \\
\hline 12-years & $\geq 1$ & 283 & $14 \%(12.5 \%, 15.5 \%)$ & 74 & $4 \%(2.8 \%, 4.5 \%)$ & 56 & $3 \%(2.1 \%, 3.6 \%)$ & 109 & $6 \%(4.5 \%, 6.6 \%)$ \\
\hline \multicolumn{10}{|c|}{$\geq 1$ Pelvic floor disorders } \\
\hline 12-years & 0 & 1031 & $60 \%(57.7 \%, 62.3 \%)$ & 461 & $27 \%(25.0 \%, 29.2 \%)$ & 132 & $9 \%(7.6 \%, 10.6 \%)$ & 528 & $35 \%(32.4 \%, 37.2 \%)$ \\
\hline 20-years & 0 & 2322 & $47 \%(45.7 \%, 48.5 \%)$ & 1051 & $22 \%(20.3 \%, 22.7 \%)$ & 265 & $6 \%(5.1 \%, 6.5 \%)$ & 1163 & $25 \%(24.0 \%, 26.5 \%)$ \\
\hline 12-years & $\geq 1$ & 1255 & $62 \%(59.7 \%, 63.9 \%)$ & 590 & $29 \%(27.4 \%, 31.4 \%)$ & 197 & $12 \%(10.1 \%, 13.1 \%)$ & 680 & $38 \%(35.8 \%, 40.3 \%)$ \\
\hline \multicolumn{10}{|c|}{$\geq 2$ Pelvic floor disorders } \\
\hline 12 -years & 0 & 298 & $17 \%(15.5 \%, 19.1 \%)$ & 60 & $3.5 \%(2.6 \%, 4.4 \%)$ & 15 & $1 \%(0.4 \%, 1.4 \%)$ & 74 & $4 \%(3.5 \%, 5.4 \%)$ \\
\hline 20-years & 0 & 743 & $15 \%(14.0 \%, 16.0 \%)$ & 167 & $3 \%(2.9 \%, 3.9 \%)$ & 25 & $0.5 \%(0.3 \%, 0.7 \%)$ & 185 & $4 \%(3.3 \%, 7.1 \%)$ \\
\hline 12-years & $\geq 1$ & 406 & $20 \%(18.3 \%, 21.7 \%)$ & 97 & $5 \%(3.9 \%, 5.7 \%)$ & 31 & $1.5 \%(1.0 \%, 2.1 \%)$ & 120 & $6 \%$ (5.1\%, 7.2\%) \\
\hline
\end{tabular}


+ Pelvic organ prolapse was defined at 12 years using responses to, "Do you have a feeling of something coming down from or in your vagina?" Any pelvic organ prolapse was defined as responses: occasionally, sometimes, most of the time, or all of the time. Bothersome pelvic organ prolapse was defined as responses: sometimes, most of the time, or all of the time. At 20 years, pelvic organ prolapse was defined using responses to, "Do you have a feeling of something bulging from your vagina?" Any pelvic organ prolapse was defined as responses: infrequently, sometimes, or often. Bothersome pelvic organ prolapse was defined as responses of sometimes or often.

++ Urinary incontinence was defined at 12 years using responses to, "Do you ever lose urine when you don't mean to?" and if yes, "in the last month how often has this happened, on average?" Any urinary incontinence was defined using responses: < 2x per month, weekly, or 3 or more times a day and bothersome urinary incontinence was defined as responses: weekly or 3 or more times a day. At 20 years, urinary incontinence was defined using responses to, "Do you have involuntary leakage of urine?" and if yes, "how often has this happened, on average?" Any incontinence was defined as responses: $<2 \mathrm{x}$ per month, weekly, 3 or more times a day and bothersome urinary incontinence was defined as responses: weekly or 3 or more times a day.

+++ Fecal incontinence was defined at 12 years using responses to the question, "Do you ever lose control of bowel motions (stool/faeces) from your back passage in between visits to the toilet?" Any fecal incontinence was defined as responses: occasionally, sometimes, most of the time, or all of the time. Bothersome FI was defined as responses most of the time and all of the time. At 20 years, having fecal incontinence was defined as responses to the Wexner scale questions, "Do you have involuntary leakage of solid faeces?" or "Do you have involuntary leakage of liquid faeces?" Any fecal incontinence was defined as responses to either question as: less than once a month (rarely), once a month but less than once a week (sometimes), greater than once a week but less than once a day (usually) or once or more every day (always). Bothersome fecal incontinence was defined using the question, "Has involuntary leakage of liquid or solid faeces influenced your feeling of frustration?" Responses of moderately or very much were considered bothersome while responses of not at all or a little were not bothersome. 
Table 2 The discriminatory ability of models predicting risk of pelvic floor disorders 12 and 20 years after birth

\begin{tabular}{|c|c|c|c|c|}
\hline \multirow{2}{*}{ Outcome } & \multirow{2}{*}{ Year } & \multicolumn{2}{|c|}{ Model Build } & \multirow{2}{*}{$\begin{array}{c}\text { Temporal } \\
\text { Validation } \\
\text { Concordance } \\
\text { index }\end{array}$} \\
\hline & & $\begin{array}{c}\text { Concordance } \\
\text { index }\end{array}$ & $95 \% \mathrm{Cl}$ & \\
\hline \multicolumn{5}{|l|}{ Pelvic organ Prolapse } \\
\hline \multirow{2}{*}{ Any } & 12 & 0.623 & $(0.591,0.653)$ & 0.598 \\
\hline & 20 & 0.680 & $(0.648,0.712)$ & 0.619 \\
\hline \multirow{2}{*}{ Bothersome } & 12 & 0.660 & $(0.612,0.706)$ & 0.598 \\
\hline & 20 & 0.736 & $(0.695,0.779)$ & 0.606 \\
\hline \multirow{2}{*}{ Treatment } & 12 & 0.734 & $(0.667,0.804)$ & 0.560 \\
\hline & 20 & 0.809 & $(0.739,0.870)$ & 0.751 \\
\hline \multirow{2}{*}{$\begin{array}{r}\text { Bothersome or } \\
\text { Treatment }\end{array}$} & 12 & 0.644 & $(0.603,0.683)$ & 0.570 \\
\hline & 20 & 0.751 & $(0.714,0.791)$ & 0.627 \\
\hline \multicolumn{5}{|l|}{ Urinary Incontinence } \\
\hline \multirow{2}{*}{ Any } & 12 & 0.672 & $(0.650,0.696)$ & 0.641 \\
\hline & 20 & 0.714 & $(0.692,0.734)$ & 0.695 \\
\hline \multirow{2}{*}{ Bothersome } & 12 & 0.702 & $(0.677,0.730)$ & 0.640 \\
\hline & 20 & 0.691 & $(0.665,0.717)$ & 0.684 \\
\hline \multirow{2}{*}{ Treatment } & 12 & 0.651 & $(0.602,0.702)$ & 0.712 \\
\hline & 20 & 0.685 & $(0.625,0.745)$ & 0.634 \\
\hline \multirow{2}{*}{$\begin{array}{r}\text { Bothersome or } \\
\text { Treatment }\end{array}$} & 12 & 0.704 & $(0.679,0.731)$ & 0.653 \\
\hline & 20 & 0.698 & $(0.673,0.724)$ & 0.689 \\
\hline \multicolumn{5}{|l|}{ Fecal Incontinence } \\
\hline \multirow{2}{*}{ Any } & 12 & 0.605 & $(0.570,0.636)$ & 0.586 \\
\hline & 20 & 0.648 & $(0.619,0.677)$ & 0.624 \\
\hline \multirow{2}{*}{ Bothersome } & 12 & 0.640 & $(0.569,0.710)$ & 0.638 \\
\hline & 20 & 0.720 & $(0.658,0.788)$ & 0.658 \\
\hline \multirow{2}{*}{ Treatment } & 12 & 0.687 & $(0.620,0.750)$ & 0.542 \\
\hline & 20 & 0.674 & $(0.571,0.759)$ & 0.642 \\
\hline Bothersome or & 12 & 0.670 & $(0.616,0.721)$ & 0.618 \\
\hline Treatment & 20 & 0.701 & $(0.644,0.759)$ & 0.676 \\
\hline \multicolumn{5}{|l|}{$\geq 1$ Pelvic Floor Disorder } \\
\hline \multirow{2}{*}{ Any } & 12 & 0.664 & $(0.643,0.688)$ & 0.650 \\
\hline & 20 & 0.700 & $(0.681,0.719)$ & 0.685 \\
\hline \multirow{2}{*}{ Bothersome } & 12 & 0.686 & $(0.663,0.713)$ & 0.643 \\
\hline & 20 & 0.693 & $(0.668,0.717)$ & 0.667 \\
\hline \multirow{2}{*}{ Treatment } & 12 & 0.670 & $(0.628,0.710)$ & 0.649 \\
\hline & 20 & 0.656 & $(0.614,0.698)$ & 0.623 \\
\hline \multirow{2}{*}{$\begin{array}{r}\text { Bothersome or } \\
\text { Treatment }\end{array}$} & 12 & 0.687 & $(0.661,0.711)$ & 0.639 \\
\hline & 20 & 0.698 & $(0.674,0.722)$ & 0.675 \\
\hline \multicolumn{5}{|l|}{$\begin{array}{l}\geq 2 \text { Pelvic Floor } \\
\text { Disorders }\end{array}$} \\
\hline \multirow{2}{*}{ Any } & 12 & 0.648 & $(0.618,0.677)$ & 0.581 \\
\hline & 20 & 0.702 & $(0.673,0.729)$ & 0.676 \\
\hline Bothersome & 12 & 0.730 & $(0.680,0.781)$ & 0.661 \\
\hline
\end{tabular}




\begin{tabular}{rcccc} 
Outcome & \multicolumn{3}{c}{ Model Build } & $\begin{array}{c}\text { Temporal } \\
\text { Validation } \\
\text { Concordance } \\
\text { index }\end{array}$ \\
\hline Treatment & Year & $\begin{array}{c}\text { Concordance } \\
\text { index }\end{array}$ & $95 \% \mathrm{Cl}$ & 0.621 \\
& 20 & 0.760 & $(0.707,0.808)$ & 0.711 \\
& 12 & 0.738 & $(0.650,0.831)$ & 0.513 \\
Bothersome or & 20 & 0.600 & $(0.507,0.744)$ & 0.635 \\
Treatment & 20 & 0.706 & $(0.644,0.751)$ & 0.619
\end{tabular}

Year 12 includes data from the ProLong dataset and year 20 includes data from SwePop dataset 


\section{ACCEPTED MANUSCRIPT}

Supplemental Table 1 Candidate predictors of pelvic floor disorders in the Swedish pregnancy, obesity and pelvic floor study and the prolapse and incontinence long-term study

\begin{tabular}{|c|c|c|c|}
\hline Variables & & $\begin{array}{r}\text { ProLong } \\
\mathrm{N}=3,763\end{array}$ & $\begin{array}{c}\text { SwePop } \\
N=4,991\end{array}$ \\
\hline \multirow{2}{*}{ Maternal Age at Delivery } & & $29(26,32)$ & $29(25,34)$ \\
\hline & Missing & $0(0 \%)$ & $0(0 \%)$ \\
\hline \multirow{2}{*}{ Maternal Pre-Pregnancy Weight (kg) } & & $60(54,67)$ & $62(56,70)$ \\
\hline & Missing & $718(19 \%)$ & $702(14 \%)$ \\
\hline \multirow[t]{2}{*}{ Maternal Height $(\mathrm{cm})$} & & $163(159,168)$ & $167(163,170)$ \\
\hline & Missing & $44(1 \%)$ & $22(0 \%)$ \\
\hline \multirow[t]{2}{*}{ Number of Previous Births } & & $1(0,1)$ & NA \\
\hline & Missing & $5(0 \%)$ & \\
\hline 0 & & $1723(46 \%)$ & \\
\hline 1 & & $1389(37 \%)$ & \\
\hline 2 & & $453(12 \%)$ & \\
\hline 3 & & $144(4 \%)$ & \\
\hline$\geq 4$ & & $49(1 \%)$ & \\
\hline \multicolumn{2}{|l|}{ Route of Delivery (Index Birth) } & $x<$ & \\
\hline & nassisted & $2556(68 \%)$ & $3061(61 \%)$ \\
\hline & Vacuum & $193(5 \%)$ & $726(15 \%)$ \\
\hline & Forceps & $401(11 \%)$ & $22(0 \%)$ \\
\hline & n Elective & $271(7 \%)$ & $764(15 \%)$ \\
\hline & ion Acute & $342(9 \%)$ & $418(8 \%)$ \\
\hline \multirow[t]{7}{*}{ Number of Past Unassisted Vaginal Deliveries } & & $1(0,2)$ & NA \\
\hline & Missing & $10(1 \%)$ & \\
\hline & 0 & $1067(28 \%)$ & \\
\hline & 1 & $1404(37 \%)$ & \\
\hline & 2 & 891 (24\%) & \\
\hline & 3 & $269(7 \%)$ & \\
\hline & $\geq 4$ & $122(3 \%)$ & \\
\hline \multirow[t]{6}{*}{ Number of Past Forceps Assisted Deliveries } & & $0(0,0)$ & NA \\
\hline & Missing & $10(1 \%)$ & \\
\hline & 0 & $2868(76 \%)$ & \\
\hline & 1 & $835(22 \%)$ & \\
\hline & 2 & $44(1 \%)$ & \\
\hline & 3 & $6(0 \%)$ & \\
\hline \multirow[t]{5}{*}{ Number of Past Vacuum Assisted Deliveries } & & $0(0,0)$ & NA \\
\hline & Missing & $10(1 \%)$ & \\
\hline & 0 & $3515(93 \%)$ & \\
\hline & 1 & $236(6 \%)$ & \\
\hline & 2 & $2(0 \%)$ & \\
\hline \multirow[t]{6}{*}{ Number of Past Planned C-Sections } & & $0(0,0)$ & NA \\
\hline & Missing & $10(0 \%)$ & \\
\hline & 0 & $3370(90 \%)$ & \\
\hline & 1 & $316(8 \%)$ & \\
\hline & 2 & $58(2 \%)$ & \\
\hline & $\geq 3$ & $9(0 \%)$ & \\
\hline \multirow[t]{3}{*}{ Number of Past Acute C-Sections } & & $0(0,0)$ & NA \\
\hline & Missing & $10(0 \%)$ & \\
\hline & 0 & $3277(87 \%)$ & \\
\hline
\end{tabular}




\begin{tabular}{|c|c|c|c|}
\hline Variables & & $\begin{array}{r}\text { ProLong } \\
\mathbf{N}=3,763\end{array}$ & $\begin{array}{c}\text { SwePop } \\
N=4,991\end{array}$ \\
\hline & 1 & $436(12 \%)$ & \\
\hline & $2 \& 3$ & $40(1 \%)$ & \\
\hline \multirow[t]{7}{*}{ Number of Any Past Vaginal Deliveries } & & $1(1,2)$ & NA \\
\hline & Missing & $10(1 \%)$ & \\
\hline & 0 & $478(13 \%)$ & \\
\hline & 1 & $1583(42 \%)$ & \\
\hline & 2 & 1169 (31\%) & \\
\hline & 3 & $365(10 \%)$ & \\
\hline & $\geq 4$ & $158(4 \%)$ & \\
\hline \multirow[t]{6}{*}{ Number of Any Past C-Sections } & & $0(0,0)$ & NA \\
\hline & Missing & $10(1 \%)$ & \\
\hline & 0 & $2999(80 \%)$ & \\
\hline & 1 & $570(15 \%)$ & \\
\hline & 2 & $149(4 \%)$ & \\
\hline & $\geq 3$ & $35(1 \%)$ & \\
\hline \multicolumn{4}{|l|}{ Family History of POP } \\
\hline & Yes & $615(16 \%)$ & $676(14 \%)$ \\
\hline & No & 2465 (66\%) & $3606(72 \%)$ \\
\hline & Missing & $683(18 \%)$ & 709 (14\%) \\
\hline \multirow[t]{4}{*}{ Family History of UI } & & NA & \\
\hline & Yes & & $1374(28 \%)$ \\
\hline & No & & $2852(57 \%)$ \\
\hline & Missing & & 765 (15\%) \\
\hline \multirow[t]{4}{*}{ Family History of FI } & & NA & \\
\hline & Yes & & $629(13 \%)$ \\
\hline & No & & 3600 (72\%) \\
\hline & Missing & & 762 (15\%) \\
\hline \multirow[t]{4}{*}{ Pre-Pregnancy UI } & & & NA \\
\hline & Yes & $382(10 \%)$ & \\
\hline & No & 3377 (90\%) & \\
\hline & Missing & $4(0 \%)$ & \\
\hline \multirow[t]{4}{*}{ UI During Pregnancy } & & & NA \\
\hline & Yes & 386 (10\%) & \\
\hline & No & 3373 (90\%) & \\
\hline & Missing & $4(0 \%)$ & \\
\hline \multirow[t]{2}{*}{ Infant Birthweight (g) } & & $3435(3080,3760)$ & $3520(3160,3960)$ \\
\hline & Missing & $75(2 \%)$ & $4(0 \%)$ \\
\hline \multirow[t]{2}{*}{ Infant Head Circumference (cm) } & & $34.7(34,35.7)$ & $35(34,36)$ \\
\hline & Missing & $148(4 \%)$ & $107(2 \%)$ \\
\hline \multirow[t]{4}{*}{ Twins } & & & NA \\
\hline & Yes & $81(2 \%)$ & \\
\hline & No & 3682 (98\%) & \\
\hline & Missing & $0(0 \%)$ & \\
\hline \multirow[t]{4}{*}{ Induction Performed } & & & NA \\
\hline & Yes & $646(17 \%)$ & \\
\hline & No & 3029 (80\%) & \\
\hline & Missing & $88(2 \%)$ & \\
\hline
\end{tabular}




\begin{tabular}{|c|c|c|c|}
\hline Variables & & $\begin{array}{r}\text { ProLong } \\
\mathrm{N}=3,763\end{array}$ & $\begin{array}{c}\text { SwePop } \\
\mathrm{N}=4,991\end{array}$ \\
\hline & Yes & $1196(32 \%)$ & $1499(30 \%)$ \\
\hline & No & $2524(67 \%)$ & $3492(70 \%)$ \\
\hline & Missing & $43(1 \%)$ & $0(0 \%)$ \\
\hline \multicolumn{4}{|l|}{ Episiotomy Performed } \\
\hline & Yes & $819(22 \%)$ & $510(10 \%)$ \\
\hline & No & $2797(74 \%)$ & $4481(90 \%)$ \\
\hline & Missing & $147(4 \%)$ & $0(0 \%)$ \\
\hline \multicolumn{4}{|c|}{ 2nd, 3rd, or 4th Degree Perineal Laceration Occurred } \\
\hline & Yes & $1430(38 \%)$ & $174(3 \%)$ \\
\hline & No & $2186(58 \%)$ & $4817(97 \%)$ \\
\hline \multirow{3}{*}{ Time in Second Stage (min.) } & Missing & $147(4 \%)$ & $0(0 \%)$ \\
\hline & & $28(8,85)$ & NA \\
\hline & Missing & $588(16 \%)$ & \\
\hline
\end{tabular}

SwePoP, Swedish Pregnancy, Obesity and Pelvic Floor (SwePOP) study; ProLong, PROlapse and incontinence LONG-term (ProLong) study; NA, Not available.

Data are $\mathrm{n}(\%)$ or median (interquartile range) unless otherwise specified. Variables are relative to the index delivery. 


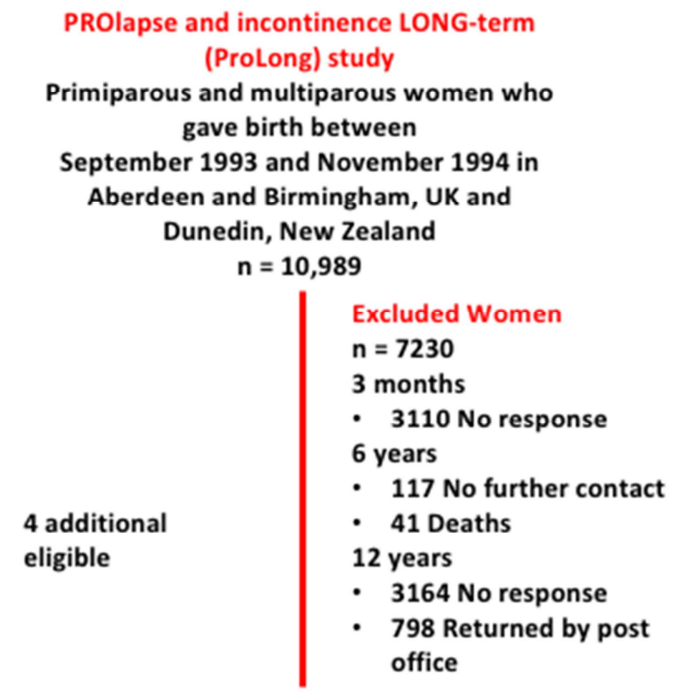

Participants Eligible for Model Build

12 years after delivery

$$
\mathrm{n}=\mathbf{3 7 6 3}
$$

Pelvic Floor Outcomes Available

12 years after delivery $n=3763$

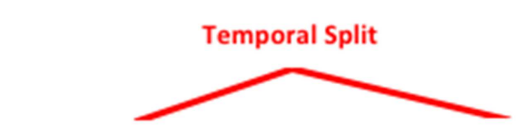

Model Build and Internal Validation

Training Set

Births between

September 11, 1993

and May 1, 1994

$\mathbf{n}=\mathbf{2 0 9 5}$

\begin{tabular}{|l}
$\quad$ Missing Da \\
$\quad \mathbf{n}=933$ (44\%) \\
Family Hx POP \\
Pre-pregnancy Weight \\
Length of Stage 2 labor \\
Fetal head \\
circumference \\
Episiotomy \\
Laceration \\
Induction \\
Epidural \\
Birth Weight \\
Maternal Height \\
Parity \\
Pre-Pregnancy UI \\
UI During Pregnancy
\end{tabular}

Primary Analysis for

Model Build after

Multiple Imputation

$\mathbf{n}=\mathbf{2 0 9 5}$
Validation Test Set

Births between

May 2, 1994 and

November 11, 1994

$$
\mathrm{n}=1668
$$

$$
\begin{aligned}
& \text { Missing Data } \\
& n=935(56 \%)
\end{aligned}
$$

\section{$350(17 \%)$}

$330(16 \%)$

$303(14 \%)$

$63(3 \%)$

$62(3 \%)$

$62(3 \%)$

$31(1 \%)$

$23(1 \%)$

22 (1\%)

21 (1\%)

$3(0 \%)$

$1(0 \%)$

$1(0 \%)$

Primary Analysis for Validation

$n=733$
Pre-pregnancy Weight Family HX POP Length of Stage 2 Labor $285(17 \%)$

Fetal head

circumference

Episiotomy

Induction

Birth Weight

Maternal Height

Epidural

Pre-Pregnancy UI

UI During Pregnancy

Parity

is for

$85(5 \%)$

$57(3 \%)$

$53(3 \%)$

23 (1\%)

$3(0 \%)$

$3(0 \%)$

$2(0 \%)$

\author{
Swedish Pregnancy, Obesity and Pelvic \\ Floor (SwePOP) study \\ Primiparous women who gave birth \\ between \\ January 1985 and December 1988 in \\ Swedish Medical Birth Register \\ $\mathrm{n}=\mathbf{1 0}, \mathbf{1 1 7}$ \\ Excluded Women \\ $\mathbf{n}=\mathbf{4 8 8 1}$ \\ - 694 No address, died or \\ secrecy \\ - 3275 No response \\ - 88 Returned by post or \\ severe illness \\ - 824 Multi-parity, multi- \\ fetal or pregnant
}

Participants Eligible for Model Build

$$
\begin{gathered}
20 \text { years after delivery } \\
\mathbf{n}=\mathbf{5 2 3 6}
\end{gathered}
$$

Pelvic Floor Outcomes Available

20 years after delivery

$$
n=4991
$$

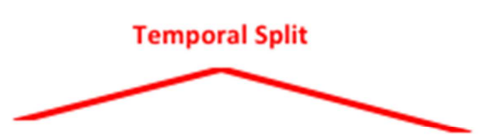

Model Build and Internal Validation

Training Set

Births between

January 1, 1985 and

June 30, 1987

$\mathrm{n}=\mathbf{2 6 0 7}$

Validation Test Set

Births between

July 1, 1987 and

December 31, 1988

$\mathbf{n}=\mathbf{2 3 8 4}$

Missing Data

$$
n=857(36 \%)
$$

$\mathbf{n}=902(35 \%)^{*}$

Family $\mathrm{Hx}$ of $\mathrm{UI}$

Family $\mathrm{Hx}$ of FI

Pre-pregnancy

Weight

Family History

of POP

Fetal head

Circumference

Maternal Height

$380(15 \%)$

Family Hx of FI $382(16 \%)$

Family Hx of UI $378(16 \%)$

$358(14 \%) \quad$ Family Hx of POP 351 (15\%)

Pre-pregnancy

$358(14 \%)$

Weight

344 (14\%)

Fetal head

$51(2 \%)$ circumference $56(2 \%)$

$15(1 \%) \quad$ Maternal Height $\quad 7(0 \%)$

20 (1\%) Birth Weight

Primary Analysis for

Model Build after

Multiple Imputation

$\mathrm{n}=\mathbf{2 6 0 7}$
$15(1 \%)$
Birth Weight $\quad 2(0 \%)$
Primary Analysis for

Validation 

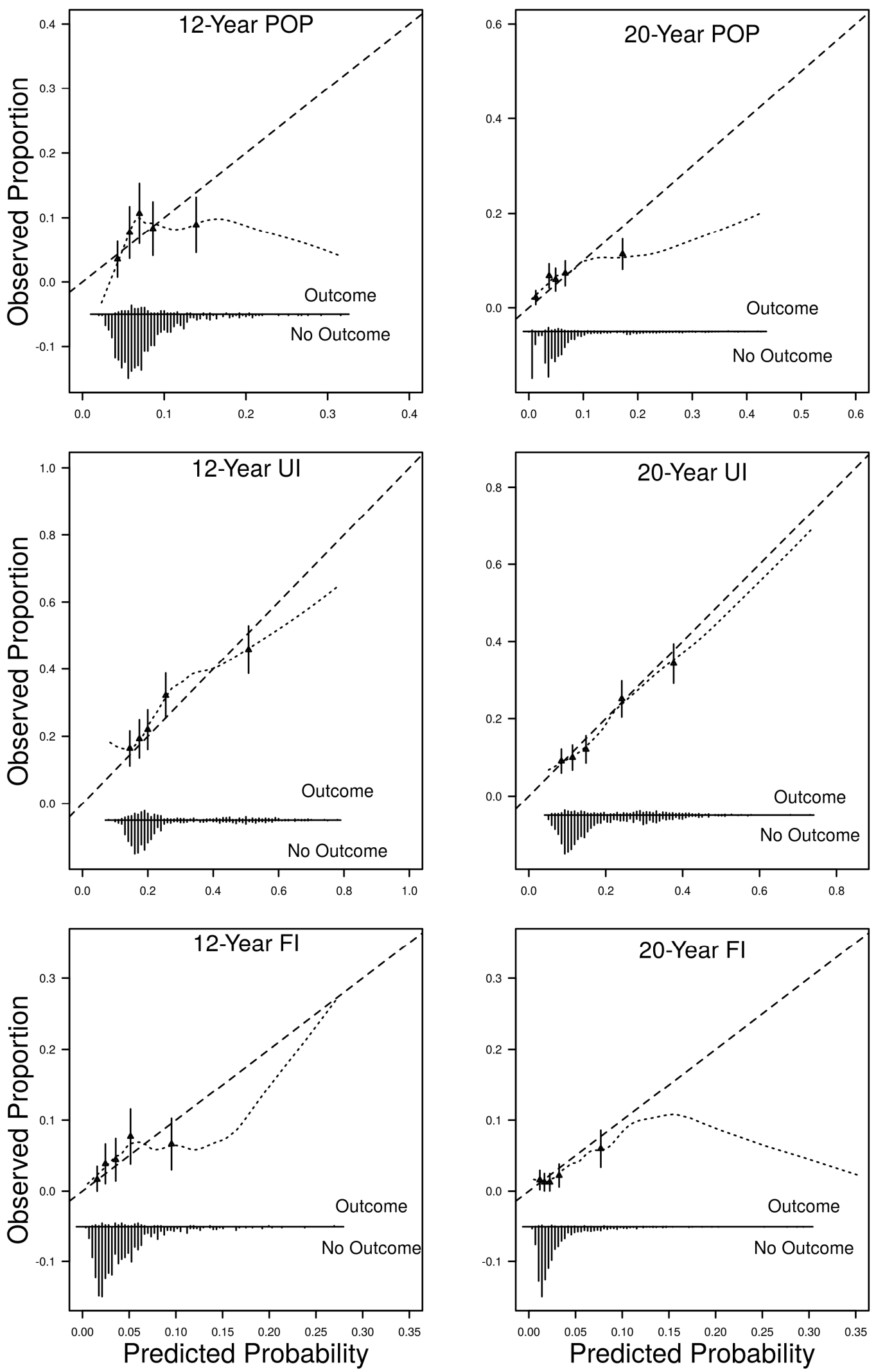


\section{ACCEPTED MANUSCRIPT}
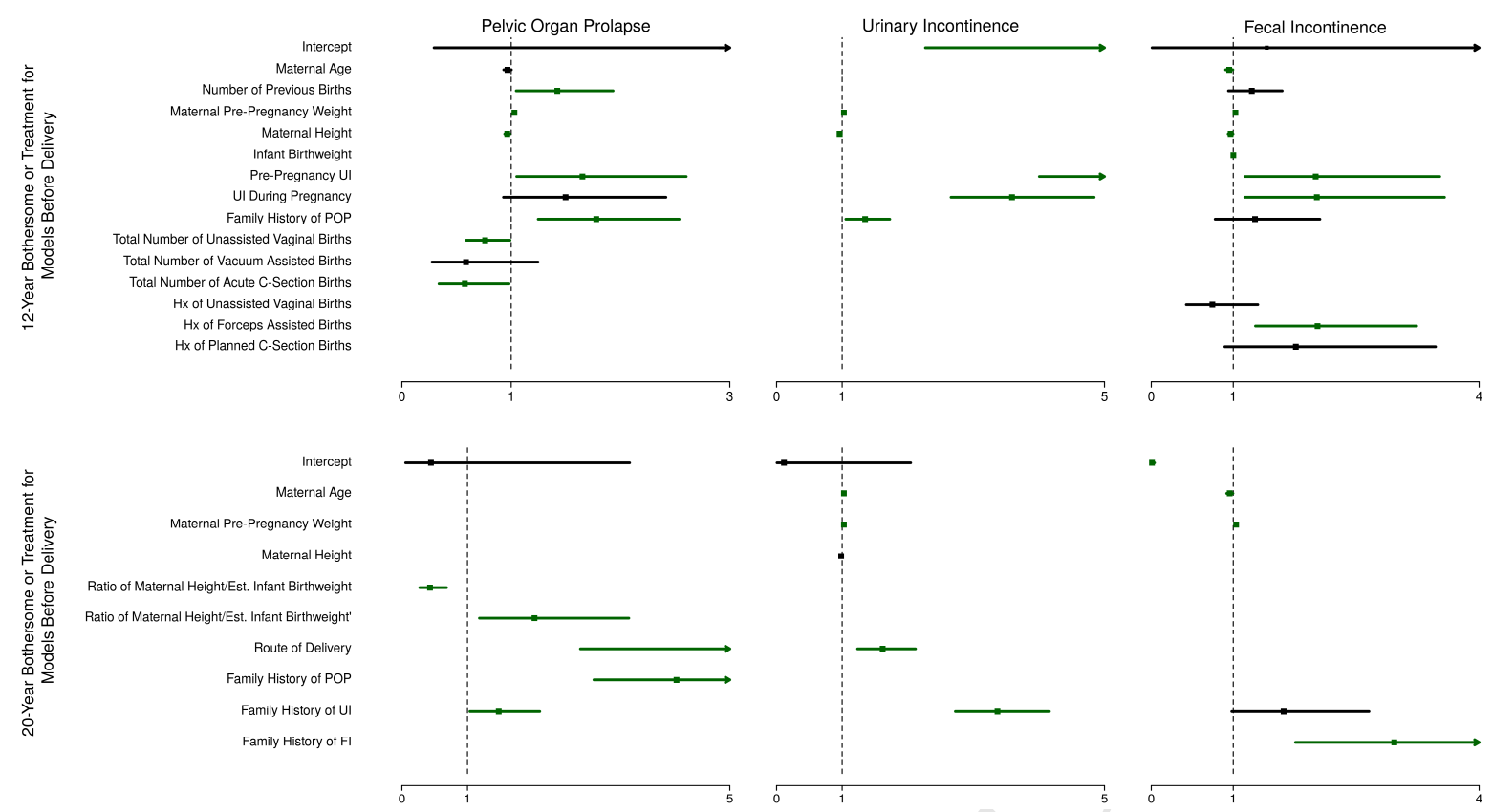

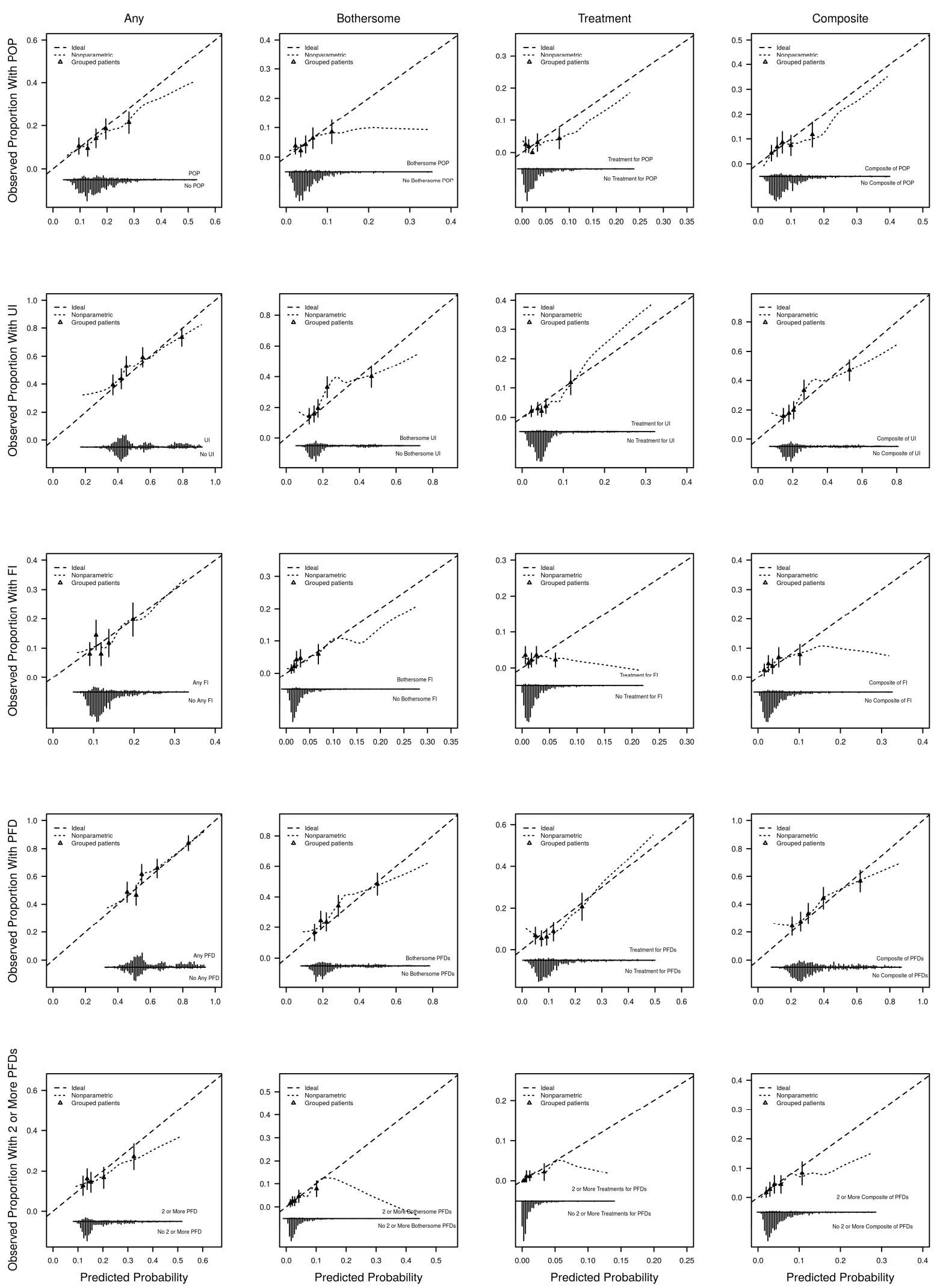

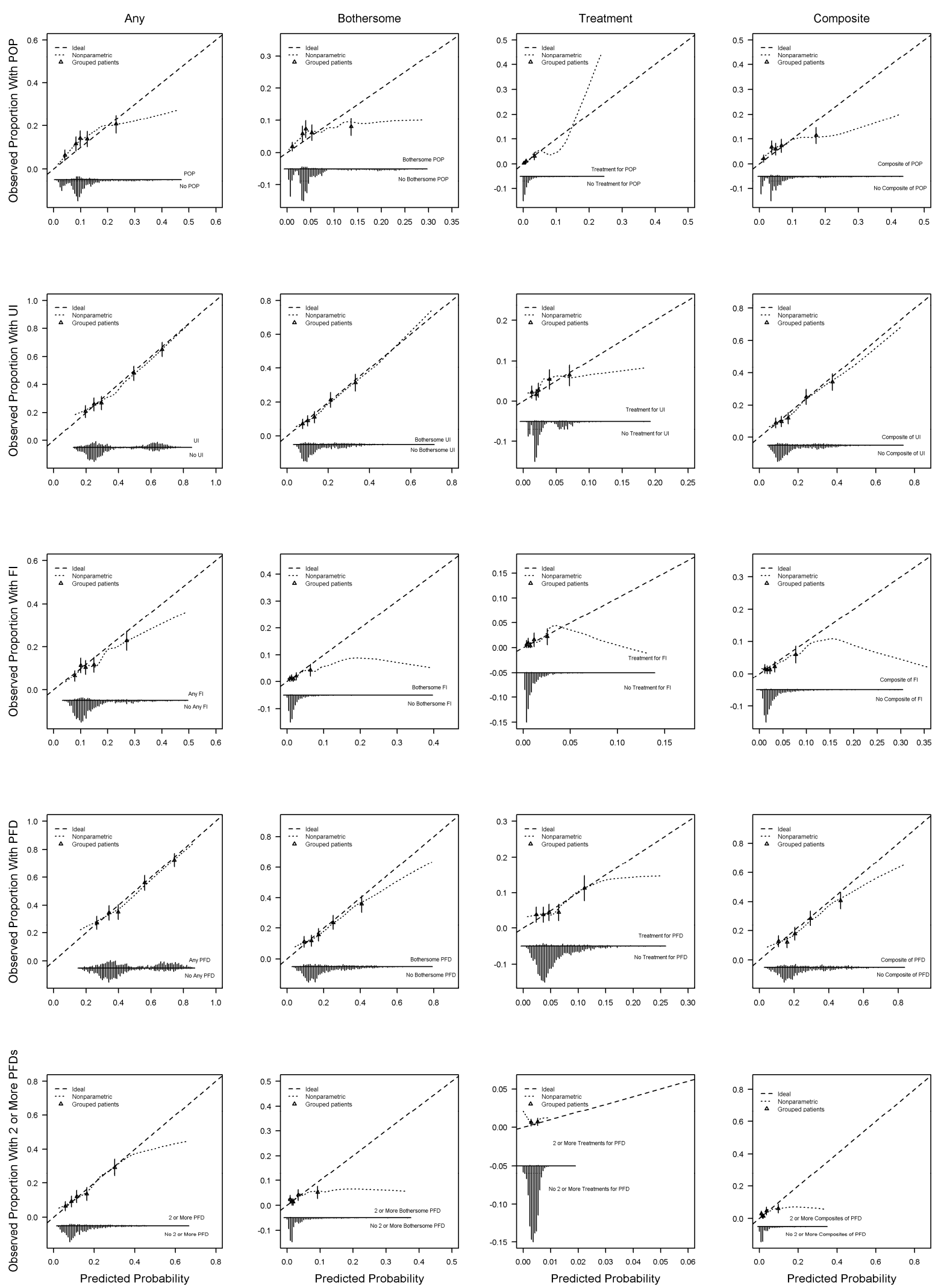


\begin{tabular}{|c|c|c|c|c|c|c|}
\hline Outcomes & $\begin{array}{c}\text { Route } \\
\text { of } \\
\text { Delivery }\end{array}$ & Any & Bothersome & Treatment & $\begin{array}{l}\text { Bothersome } \\
\text { or Treatment }\end{array}$ & $\begin{array}{c}\text { Average Risk } \\
\text { of } \\
\text { Bothersome } \\
\text { or Treatment }\end{array}$ \\
\hline \multirow{2}{*}{$\begin{array}{l}\text { Pelvic Organ } \\
\text { Prolapse }\end{array}$} & Vaginal & $10 \%$ & $3 \%$ & $1 \%$ & $4 \%$ & $9 \%$ \\
\hline & C-Section & $3 \%$ & $1 \%$ & $<0.5 \%$ & $1 \%$ & $3 \%$ \\
\hline \multirow{2}{*}{$\begin{array}{c}\text { Urinary } \\
\text { Incontinence }\end{array}$} & Vaginal & $30 \%$ & $14 \%$ & $2 \%$ & $15 \%$ & $20 \%$ \\
\hline & C-Section & $20 \%$ & $10 \%$ & $1 \%$ & $10 \%$ & $15 \%$ \\
\hline \multirow{2}{*}{$\begin{array}{c}\text { Fecal } \\
\text { Incontinence }\end{array}$} & Vaginal & $14 \%$ & $3 \%$ & $1 \% *$ & $2 \%$ & $3 \%$ \\
\hline & C-Section & $10 \%$ & $1 \%$ & $2 \% *$ & $2 \%$ & $3 \%$ \\
\hline \multirow{2}{*}{$\begin{array}{l}\text { Any Pelvic } \\
\text { Floor } \\
\text { Disorder }\end{array}$} & Vaginal & $40 \%$ & $18 \%$ & $4 \%$ & $20 \%$ & $27 \%$ \\
\hline & C-Section & $26 \%$ & $10 \%$ & $2 \%$ & $12 \%$ & $18 \%$ \\
\hline \multirow{2}{*}{$\begin{array}{l}\text { Two or More } \\
\text { Pelvic Floor } \\
\text { Disorders }\end{array}$} & Vaginal & $13 \%$ & $2 \%$ & $<0.5 \%$ & $2 \%$ & $4 \%$ \\
\hline & C-Section & $6 \%$ & $1 \%$ & $<0.5 \%$ & $1 \%$ & $2 \%$ \\
\hline
\end{tabular}




\begin{tabular}{|c|c|c|c|c|c|c|}
\hline Outcomes & $\begin{array}{l}\begin{array}{l}\text { Route } \\
\text { of }\end{array} \\
\text { Delivery }\end{array}$ & Any & Bothersome & Treatment & $\begin{array}{l}\text { Bothersome } \\
\text { or Treatment }\end{array}$ & $\begin{array}{c}\text { Average Risk } \\
\text { of } \\
\text { Bothersome } \\
\text { or Treatment }\end{array}$ \\
\hline \multirow{2}{*}{$\begin{array}{l}\text { Pelvic Organ } \\
\text { Prolapse }\end{array}$} & Vaginal & $29 \%$ & $>10 \%$ & $3 \%$ & $20 \%$ & $9 \%$ \\
\hline & C-Section & $12 \%$ & $5 \%$ & $<0.5 \%$ & $5 \%$ & $3 \%$ \\
\hline \multirow{2}{*}{$\begin{array}{c}\text { Urinary } \\
\text { Incontinence }\end{array}$} & Vaginal & $68 \%$ & $33 \%$ & $7 \%$ & $>30 \%$ & $20 \%$ \\
\hline & C-Section & $55 \%$ & $25 \%$ & $3 \%$ & $27 \%$ & $15 \%$ \\
\hline \multirow{2}{*}{$\begin{array}{c}\text { Fecal } \\
\text { Incontinence }\end{array}$} & Vaginal & $14 \%$ & $3 \%$ & $1 \% *$ & $4 \%$ & $3 \%$ \\
\hline & C-Section & $10 \%$ & $1 \%$ & $2 \% *$ & $4 \%$ & $3 \%$ \\
\hline \multirow{2}{*}{$\begin{array}{l}\text { Any Pelvic } \\
\text { Floor } \\
\text { Disorder }\end{array}$} & Vaginal & $72 \%$ & $>40 \%$ & $10 \%$ & $48 \%$ & $27 \%$ \\
\hline & C-Section & $57 \%$ & $28 \%$ & $6 \%$ & $33 \%$ & $18 \%$ \\
\hline \multirow{2}{*}{$\begin{array}{l}\text { Two or More } \\
\text { Pelvic Floor } \\
\text { Disorders }\end{array}$} & Vaginal & $32 \%$ & $>10 \%$ & $<0.5 \%$ & $>10 \%$ & $4 \%$ \\
\hline & C-Section & $17 \%$ & $5 \%$ & $<0.5 \%$ & $6 \%$ & $2 \%$ \\
\hline
\end{tabular}



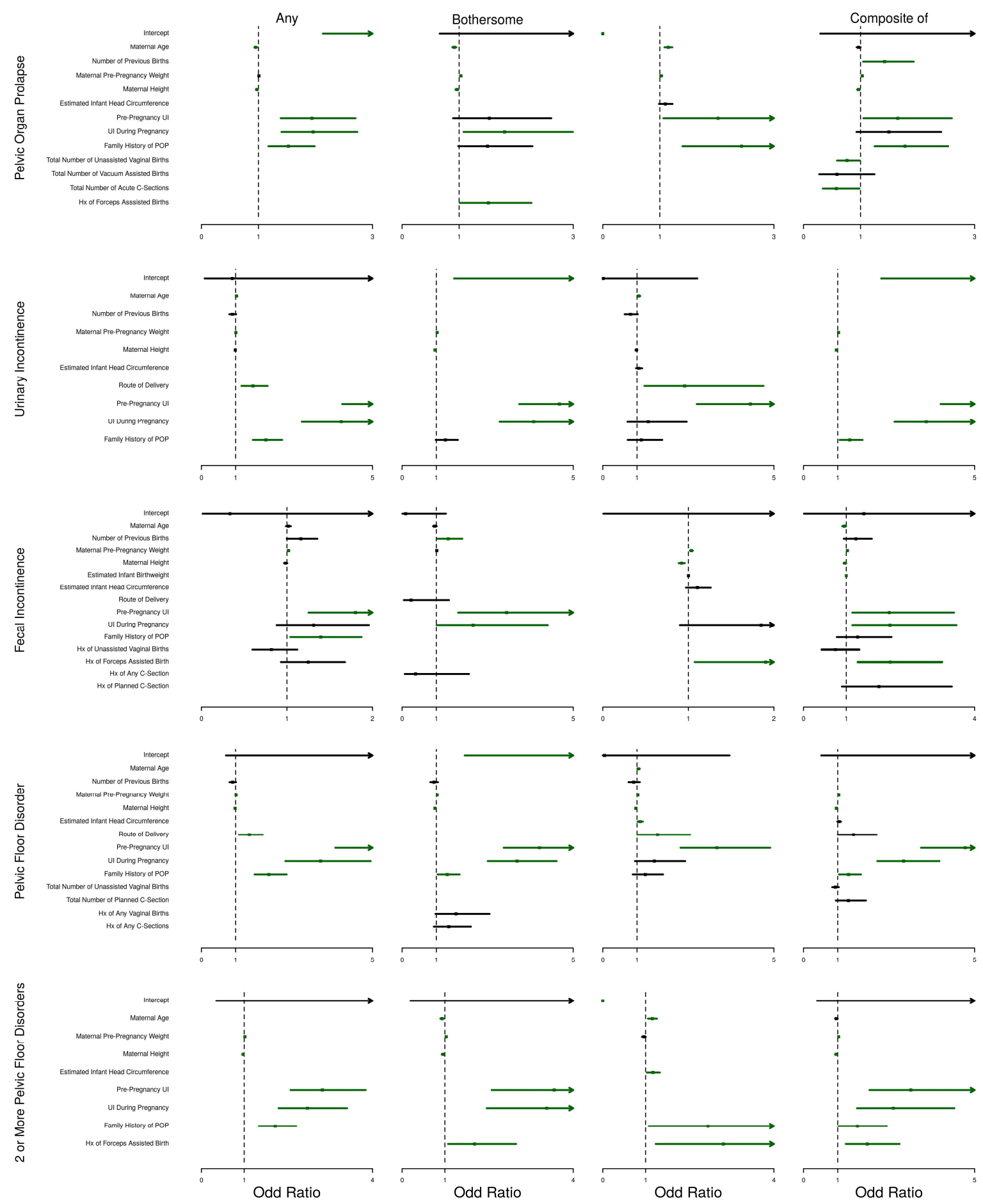

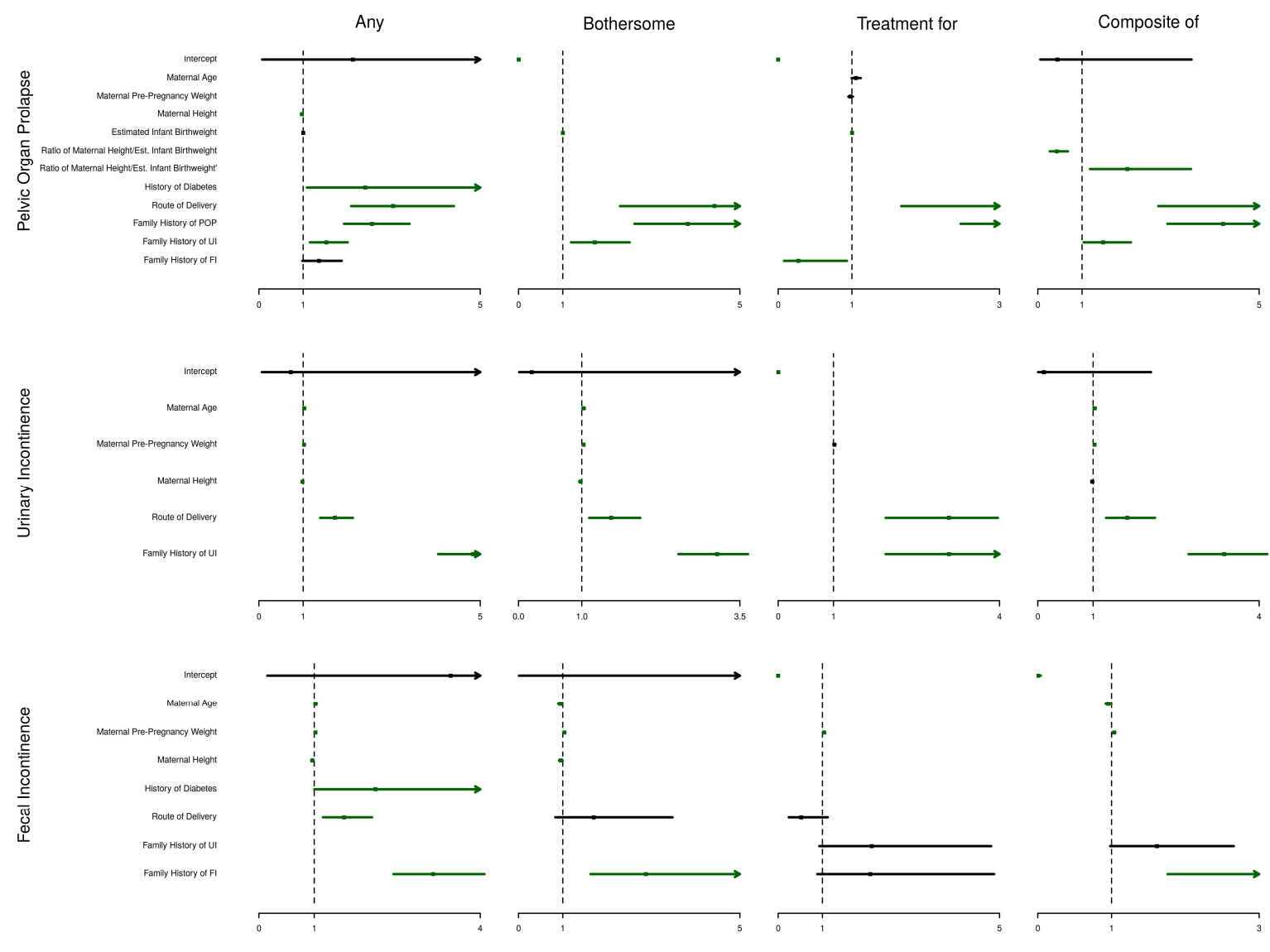

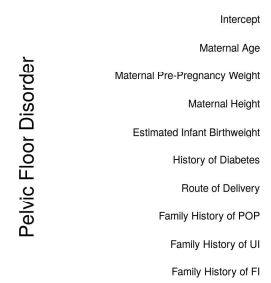
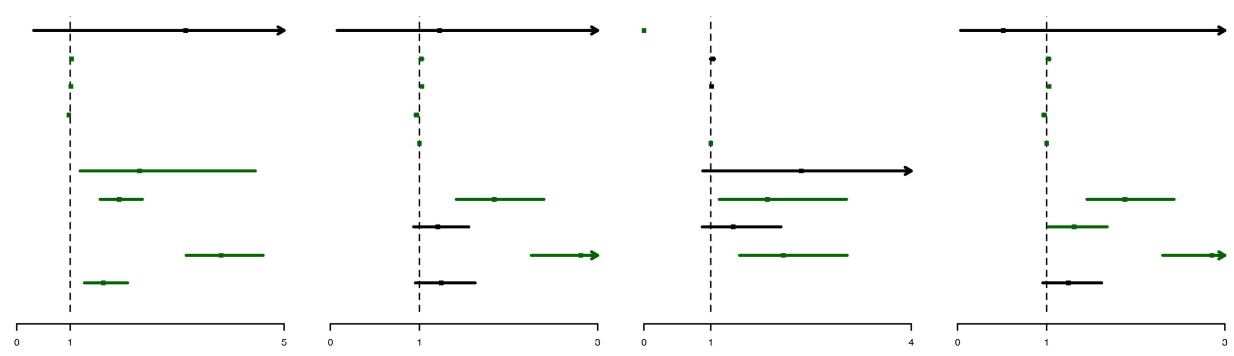

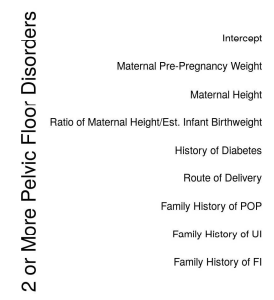
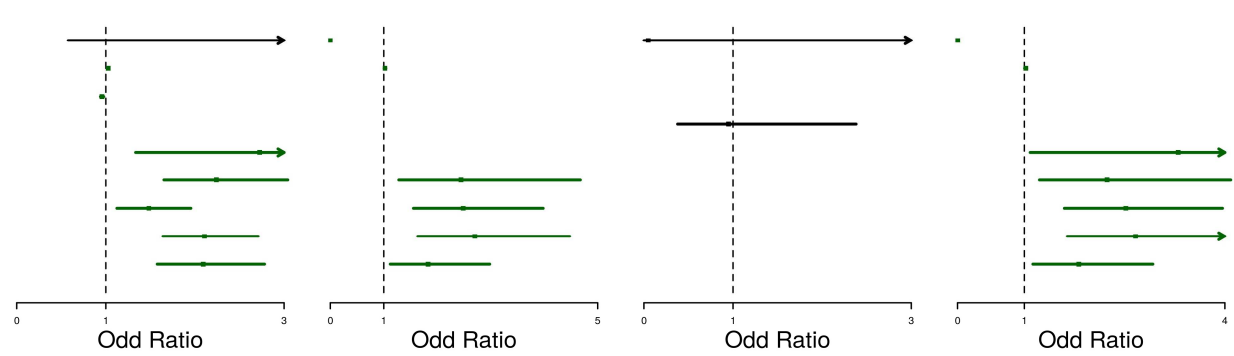